\title{
Real-Time Monitoring of the Effects of Telmisartan on Angiotensin II-Induced Mechanical Changes in Live Mesangial Cells Using Atomic Force Microscopy
}

\author{
Kyung-Hwan Jeong ${ }^{\mathrm{a}}$ Tae-Won Lee ${ }^{\mathrm{a}}$ Chun-Gyoo $\mathrm{Ihm}^{\mathrm{a}}$ Joo-Young Moon ${ }^{\mathrm{a}}$ \\ Gi-Ja Lee ${ }^{b}$ Hun-Kuk Park ${ }^{b}$ Sang-Ho Lee ${ }^{a}$ \\ Departments of a Nephrology and ${ }^{b}$ Biomedical Engineering and Healthcare Industry Research Institute, \\ College of Medicine, Kyung Hee University, Seoul, Korea
}

\section{Key Words}

Angiotensin II $\cdot$ Angiotensin receptor blocker $\cdot$ Atomic force microscopy $\cdot$ Mesangial cell $\cdot$ Real-time monitoring • Telmisartan

\begin{abstract}
Background/Aims: Recent studies have shown that angiotensin II (Ang II) type 1 receptor blockers (ARB) may provide renal protection independent of their blood pressure-lowering effect. However, evidence for this comes from indirect methods, such as genetic or protein expression studies. In this study, we hypothesized that telmisartan, a specific ARB, applied to Ang II-stimulated mesangial cell (MC) would exert a renoprotective effect via modulation of MCs' mechanical properties. Methods: We investigated the effect of telmisartan on Ang II-induced changes in MCs utilizing real-time atomic force microscopy (AFM) imaging and force-distance curve measurements. Results: Real-time AFM images of live MCs demonstrated that cells contracted towards the center after Ang II exposure, and telmisartan treatment abolished this change. Cellular spring constants showed that telmisartan prevented Ang II-induced MC stiffening (Ang II: $0.109 \pm$
\end{abstract}

$0.019 \mathrm{~N} / \mathrm{m}$, Ang II + telmisartan: $0.051 \pm 0.016 \mathrm{~N} / \mathrm{m}, \mathrm{p}<$ 0.005). Telmisartan-treated MCs had a significantly lower adhesion force than those of the control group (control: $0.49 \pm$ $0.22 \mathrm{nN}$, telmisartan: $0.22 \pm 0.06 \mathrm{nN}$, Ang II: $0.40 \pm 0.25 \mathrm{nN}$, Ang II + telmisartan: $0.27 \pm 0.14 \mathrm{nN}, \mathrm{p}<0.005$ ). These results demonstrate that the dynamic contraction and mechanical properties of Ang II-stimulated MCs are restored by telmisartan. Conclusions: We report for the first time the use of AFM force-distance curves on live MCs to directly monitor changes in surface adhesion and stiffness of cells after treatment with telmisartan in real time.

Copyright $\odot 2012$ S. Karger AG, Basel

\section{Introduction}

Angiotensin II (Ang II) is an important regulator involved in renal injury; its most significant effect is a direct contractive action on glomerular mesangial cells (MCs). It is thought that the contraction of MCs in the glomerulus decreases capillary surface area, resulting in reduced glomerular filtration rate [1]. Furthermore, increased contractibility may be a causative factor in the promotion

\section{KARGER}

Fax +41613061234 E-Mail karger@karger.ch www.karger.com
(C) 2012 S. Karger AG, Basel

$1420-4096 / 12 / 0356-0573 \$ 38.00 / 0$

Accessible online at:

www.karger.com/kbr
Sang-Ho Lee

Department of Nephrology, College of Medicine, Kyung Hee University

1 , Hoegi-dong, Dongdaemun-gu

Seoul 130-701 (Korea)

Tel. +82 2958 8200, E-Mail rulale@ dreamwiz.com 
of adhesion assembly in cells, and, as a result, may lead to increased cell adhesion [2]. These effects are known to be Ang II type $1\left(\mathrm{AT}_{1}\right)$ receptor-mediated, and it is now widely recognized that Ang II receptor blockers (ARBs) have renoprotective effects [3, 4]. Telmisartan, a specific $\mathrm{ARB}$, was recently reported to prevent glomerular injury in various models of experimental renal disease $[5,6]$. The renoprotective effect of telmisartan is thought to be due to a direct effect on MCs. However, it has not yet been determined whether telmisartan inhibits Ang II-induced MC contractibility and morphologic changes.

Since the invention of atomic force microscopy (AFM) by Binnig et al. [7], this technique has been recognized as an important imaging tool in biological research. Measurement of the force between the probe tip of AFM and sample, by means of force-distance curves, is important in defining a sample's physical properties. Thus, AFM force curves can be used to evaluate the stiffness and adhesive properties of cell membranes [8]. In renal physiology, AFM is predominantly used to image intact renal cells and study subcellular structures. While these experiments continue, they are now complemented by studies of other aspects of cell function, such as measurement of cellular stiffness $[9,10]$.

There has been significant research into the effects of ARBs on MCs in response to diverse injuries, however, studies demonstrating in real time the direct mechanical changes induced by ARB treatment and live MC injury are rare. Recently, we used AFM to observe Ang II-induced conformational changes in live and fixed MCs [11] in which force-distance analysis was employed to evaluate the elastic changes in MCs induced by Ang II. Currier et al. [12] also demonstrated that $\mathrm{AT}_{1}$ receptor stimulation with Ang II produced a contractile response in HEK cells. This could be abolished with an inhibitor of the $\mathrm{AT}_{1}$ receptor, but there is limited data on the role of ARB in MC contraction.

Based on the above findings, we hypothesized that telmisartan would prevent Ang II-induced MC contraction. Using AFM, we investigated the effects of telmisartan on the Ang II-induced mechanical changes in live MCs. In addition, this study was undertaken to define the specific effects of telmisartan on live MC contractibility and the subsequent impacts on cell stiffness and adhesiveness. In this study, we focused on real-time AFM imaging of single live cell dynamics and mechanical changes in live cells to examine the telmisartan effect on Ang II-induced MC injury.

\section{Materials and Methods}

\section{Cell Culture and Drug Treatment}

Rat MCs were isolated from 5- to 7-week-old male SpragueDawley rats using a conventional method as previously reported [13]. Isolated MCs (passages 4-6) were cultured in Dulbecco's modified Eagle's medium (DMEM; Gibco-Invitrogen, Calif., USA) containing $20 \%$ fetal bovine serum and penicillin-streptomycin in a humidified $5 \% \mathrm{CO}_{2}$ incubator at $37^{\circ} \mathrm{C}$. In preparation for AFM observation, MCs were plated on a collagen type I-coated $60-\mathrm{mm}$ culture dish and were incubated for $48 \mathrm{~h}$. After cells reached confluence, they were washed once with phosphate-buffered saline (PBS, pH 7.4), and new DMEM was added. Cells were then incubated with Ang II (Sigma-Aldrich, St. Louis, Mo., USA) and telmisartan (Sigma-Aldrich) at the same concentrations $(1 \times$ $10^{-6} \mathrm{M}$ ), with Ang II being administered $10 \mathrm{~min}$ after preincubation with telmisartan. Changes in cell stiffness and adhesive force were subsequently analyzed for $20 \mathrm{~min}$.

\section{AFM Observations}

AFM images were obtained using a NanoStation II (Surface Imaging Systems, Herzogenrath, Germany) in contact mode. Reflective side gold-coated silicon probes with a spring constant of $0.2 \mathrm{~N} / \mathrm{m}$ (Applied NanoStructures, Inc., Santa Clara, Calif., USA) were used for AFM imaging and force-distance curve measurement. We could not use less stiff cantilever such as silicon nitride. Instead, we optimized the load force and scan rate for the realtime imaging of live cell, as well as the scan range of force-distance curve measurement for live cell. The tip radius of the silicon cantilever is under $10 \mathrm{~nm}$. For measurements in liquid solution, reflective side gold-coated silicon cantilevers were used. The AFM probes were stabilized with DMEM or PBS for at least $10 \mathrm{~min}$ prior to scanning.

Live MCs were scanned in DMEM solution buffered with HEPES at a resolution of $256 \times 256$ pixels and a scan rate of 3 lines/s. It takes $85 \mathrm{~s}$ to obtain one AFM image of a live cell. Imaging of live cells was performed at $32-34^{\circ} \mathrm{C}$ in an isothermal-isohumidity control room to maintain cell survival. We used one culture dish within $1 \mathrm{~h}$ to maintain cell viability and to evaluate real-time imaging. The loading force was adjusted to $<1-2 \mathrm{nN}$ to minimize cell damage. Because live cells are easily deformed by external force, we experimentally optimized the loading force for live MC imaging. In order to evaluate the telmisartan effect, MCs were pretreated with telmisartan for $10 \mathrm{~min}$ before Ang II stimulation. Real-time AFM imaging was performed at 10-min intervals for $20 \mathrm{~min}$ after Ang II stimulation. We performed real-time imaging three times $(0,10,20 \mathrm{~min})$ on five independent cells for each groups. We obtained 15 real-time images in each group.

To measure changes in cell stiffness and adhesion, force-distance curves were obtained for live MCs. Young's modulus of cells by the Hertz model should be calculated with many assumptions. Therefore, we calculated the spring constant of the cells from the slope of the force-distance curve as previously reported $[8,14]$. The cantilever spring constant is determined from a force-distance curve about each cantilever using a clean culture dish containing DMEM. It was rechecked after cell measurements to confirm the integrity of the tip.

In principle, AFM was used as a mechanical tool, whereby the AFM tip was pressed against the cell such that the membrane was indented, thereby distorting the AFM cantilever, which serves as 


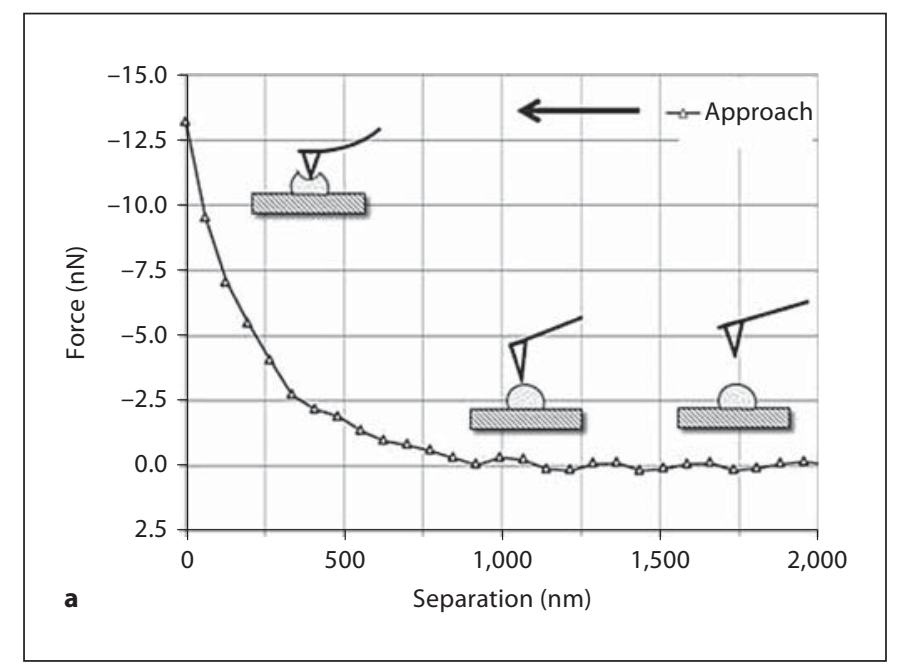

Fig. 1. Force-distance curves obtained in a single MC. a The slope of the approach curve: the AFM tip is moved vertically towards the cell. After the AFM tip has engaged against the cell surface, the cantilever bends upward when the cell is indented. $\mathbf{b}$ The slope

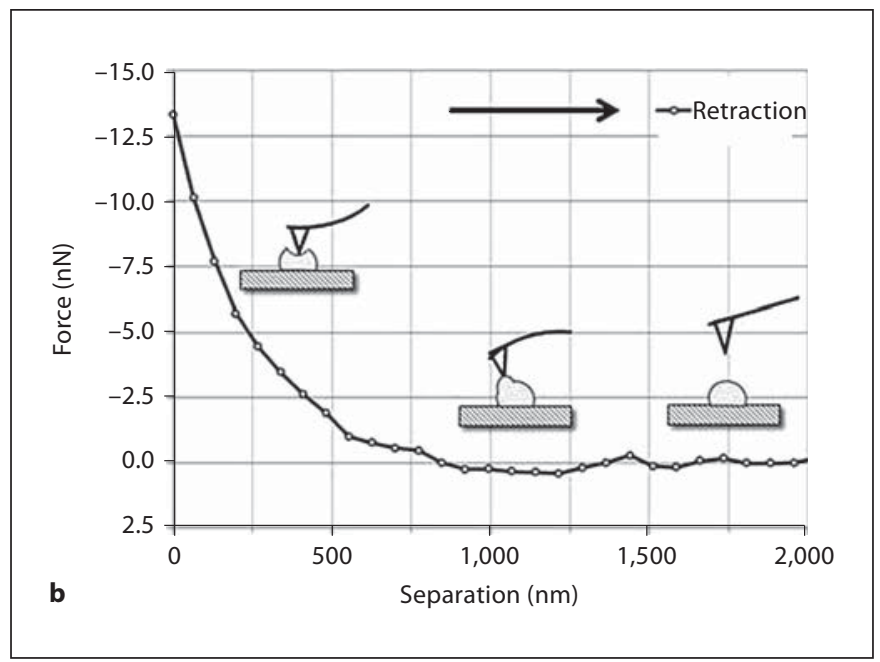

of the retraction curve: the AFM tip is moved vertically away from cell. When the AFM tip was retracted from the cell, adhesion occurred between the probe and the cell surface. The adhesion force caused the cantilever to bend downward. a spring constant. The actual interaction range between its probe tip and the cell was approximately 500-1,000 nm, depending on cell stiffness. The resulting cantilever deflection allows for generation of force-distance curves for single cells (fig. 1). The slope of the approach curve (fig. 1a), the first half of the force-distance curve where the tip approaches the cells, was defined as the stiffness of a single cell. The slope of approach curves is directly related to the force necessary to indent the cell maximally for a given distance. The retraction curve (fig. 1b), the second half of the force-distance curve where the tip pulls away from the cell, was used to determine the adhesion force. Adhesion occurred between the probe and the cell surface; the adhesion force caused the cantilever to bend downward.

Stiffness and adhesive forces were examined for every approach or retraction curve, and averages with standard deviations (SD) were calculated. We obtained force-distance curve measurements at 5-10 locations per cell according to cell size and morphology. The mean value of the force-distance curve measurements was considered as the representative value of one cell. Thirty cells in each group were used to measure the mechanical changes in cells after Ang II and telmisartan administration. Force-distance curves were measured at multiple locations with similar distances from the center of the cell in order to avoid edge effects. After force curves were obtained, a second image was evaluated to ensure that the cell had not ruptured or shifted.

\section{Statistics}

The calculated stiffness and adhesive forces of live MCs are expressed as mean \pm SD. ANOVA was used to evaluate the significance of differences among groups. All $\mathrm{p}$ values were twosided, and values $<0.05$ were considered statistically significant. Data analysis was performed using SPSS software version 15.0.

\section{Results}

\section{Morphological Changes in Live MCs upon Treatment with Ang II and ARBS}

We used contact mode AFM in DMEM solution with no chemical fixation or mechanical trapping to observe real-time images of live MCs after Ang II stimulation with or without telmisartan. We monitored real-time cell response at 10-min intervals for $20 \mathrm{~min}$ after Ang II stimulation with or without telmisartan (fig. 2,3). Figure 2 is a time series of topography and deflection images of MCs in real time over a $50 \times 50 \mu \mathrm{m}$ scan area. From the AFM topography images, MCs are from 1 to $2.5 \mu \mathrm{m}$ in height. Live MCs exhibited the expected contractile characteristics induced by Ang II, including a gradual contraction towards the center, as shown in the time sequence images and the height profile plot of figure 2 . As seen in the profile, cell contraction caused movement toward the cell center and gradually changed cell height $(1.58 \mu \mathrm{m}$ at $0 \mathrm{~min}, 1.19 \mu \mathrm{m}$ at $10 \mathrm{~min}$, and $0.62 \mu \mathrm{m}$ at $20 \mathrm{~min}$ ) in the cellular edge region. There was steady movement of the cell towards the cell center, with the bottom of culture dish gradually exposed. In order to determine whether such changes in MC contraction could be abolished via ARB treatment, cells were pretreated with telmisartan prior to Ang II stimulation. The Ang II-induced contractile changes in MCs were disrupted by telmisartan pretreatment in real time (fig. 3). As expected, prevention of 


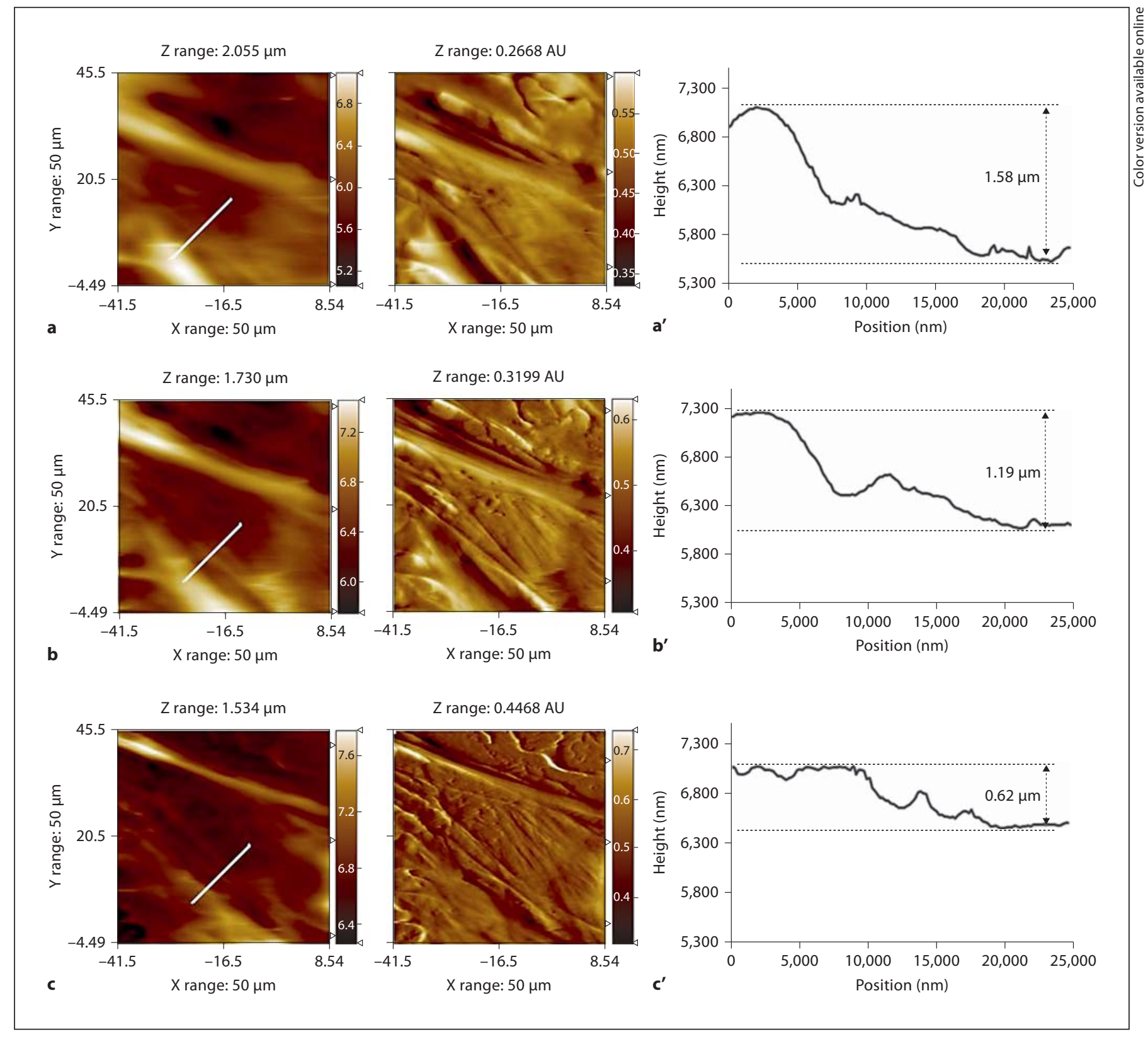

Fig. 2. Successive sequence of topography (left panel) and deflection (right panel) images of live MCs at the edge region (a-c) and height profiles of the indicated lines $\left(\mathbf{a}^{\prime}-\mathbf{c}^{\prime}\right)$ : before Ang II (a, $\left.\mathbf{a}^{\prime}\right), 10 \mathrm{~min}\left(\mathbf{b}, \mathbf{b}^{\prime}\right)$, and $20 \mathrm{~min}(\mathbf{c}$, $\left.\mathbf{c}^{\prime}\right)$ after Ang II treatment.

contraction led to diminished changes in the cell height profile (fig. $3,2.33 \mu \mathrm{m}$ at $0 \mathrm{~min}, 2.41 \mu \mathrm{m}$ at $10 \mathrm{~min}$, and $2.42 \mu \mathrm{m}$ at $20 \mathrm{~min}$ ). As shown in figure 4, telmisartan alone had no significant effect on MC contraction or changes in cell height. In this study, we did not utilize cell height as a parameter, but rather as an indicator of cell movement. As the height of individual cells showed large variation, we could not statistically analyze the difference in cell height between treatments.

\section{Mechanical Changes in Live MCs Induced by Ang II} and $A R B$

From the AFM imaging result, we chose the force-distance curve measurement time in which the Ang II-in- 


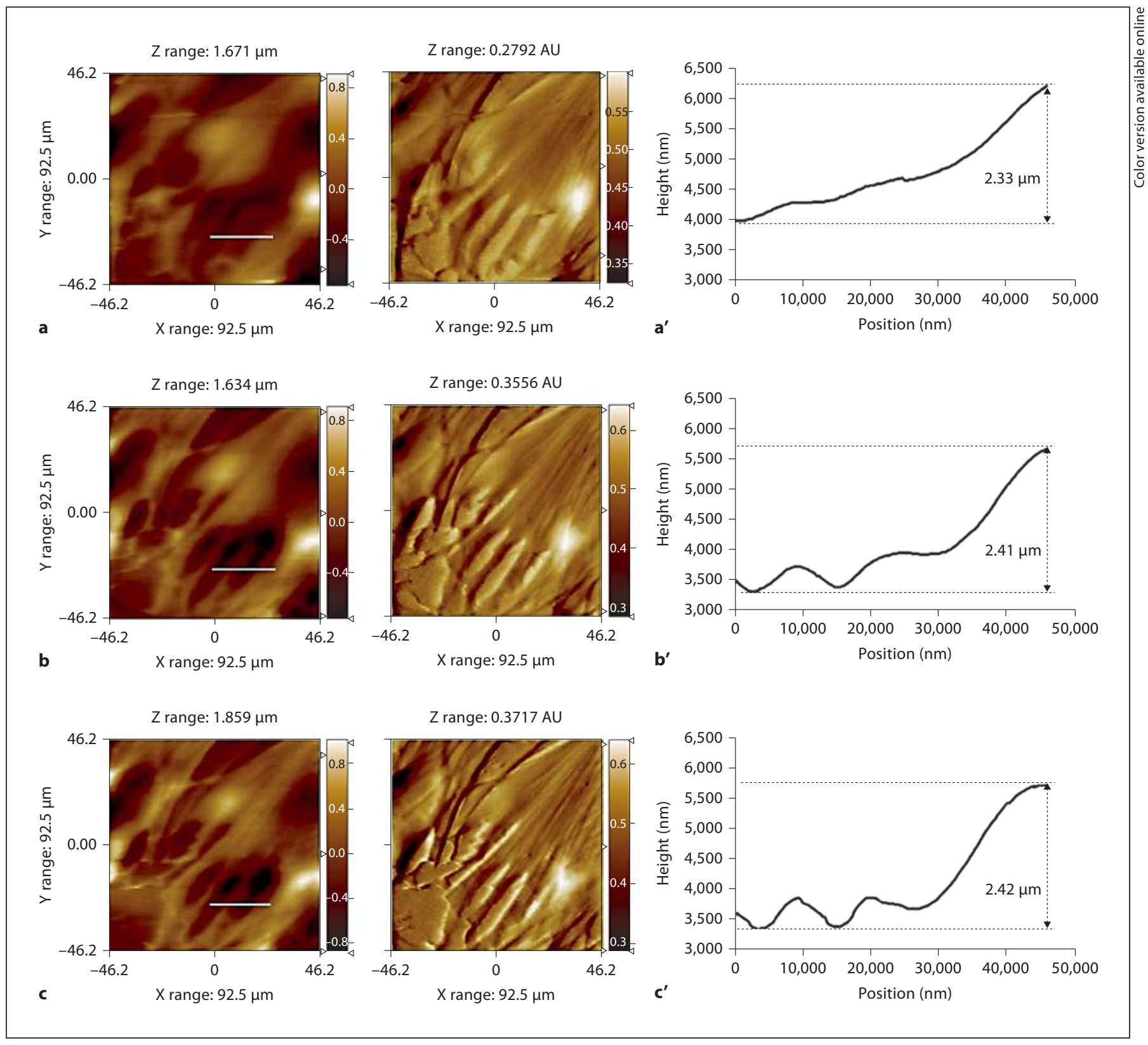

Fig. 3. Successive sequence of topography (left panel) and deflection (right panel) images of live MCs at the edge region (a-c) and height profiles of the indicated lines $\left(\mathbf{a}^{\prime}-\mathbf{c}^{\prime}\right)$ : before Ang II (a, $\left.\mathbf{a}^{\prime}\right), 10 \mathrm{~min}\left(\mathbf{b}, \mathbf{b}^{\prime}\right)$, and $20 \mathrm{~min}(\mathbf{c}$, $\left.\mathbf{c}^{\prime}\right)$ after Ang II stimulation under telmisartan pretreatment.

duced change clearly appeared (20 min after Ang II stimulation). In this study, force-distance measurements were obtained for 30 cells in each group. The AFM tip was precisely positioned over the center (apical region) of individual cells to minimize the variation in cellular response associated with the diverse geometry observed throughout the cell surface.

Real-Time Monitoring of ARB Effects in Live Mesangial Cells
Figure 5 shows the distributions of spring constants calculated from the force-distance curve in control MCs without any treatment, telmisartan or Ang II-stimulated cells, and cells treated with a combination of Ang II and telmisartan. The slope of the linear portion of each approach curve was used to determine the stiffness of the cell, expressed as an average cellular spring constant

Kidney Blood Press Res 2012;35:573-582 


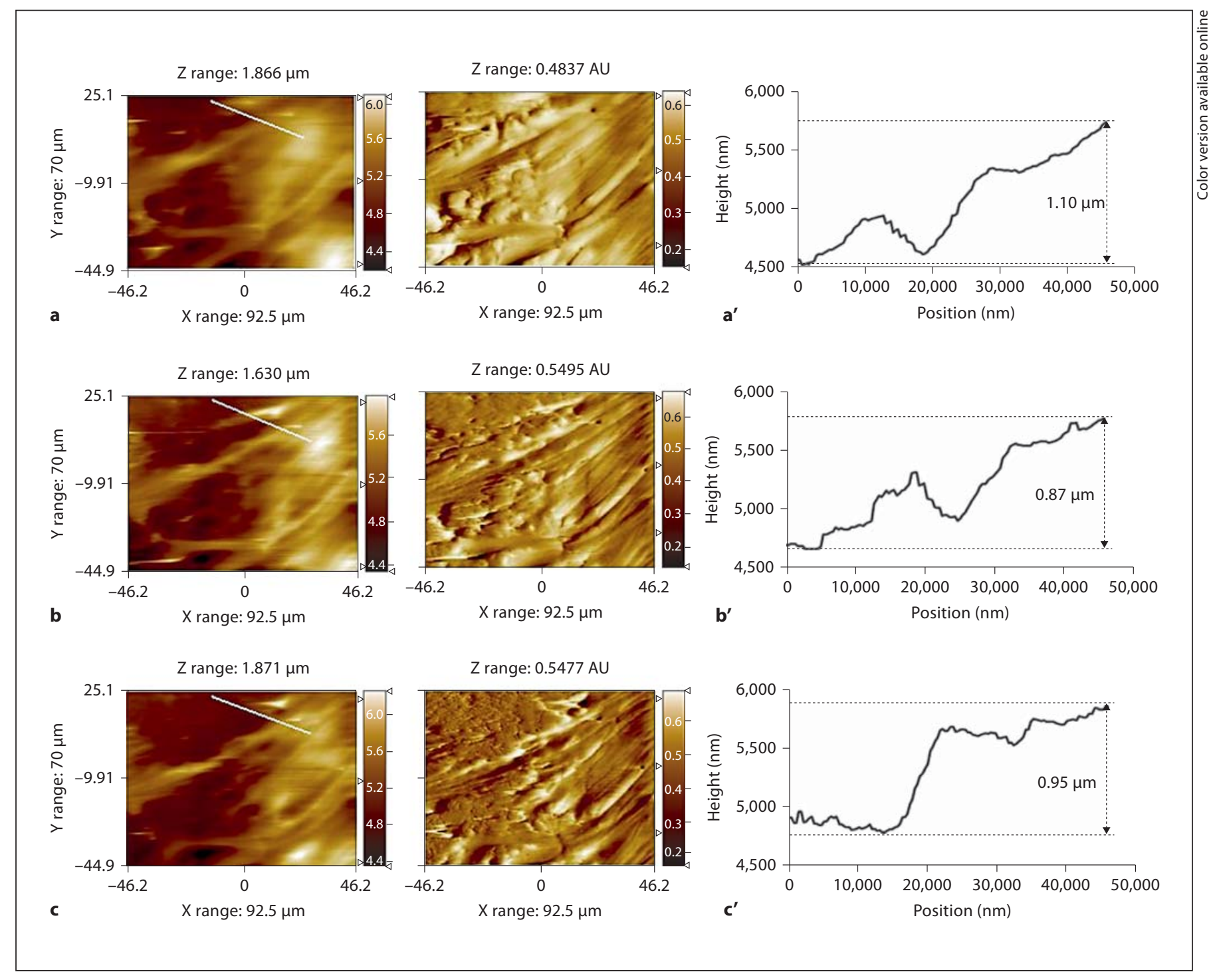

Fig. 4. Successive sequence of topography (left panel) and deflection (right panel) images of live MCs at the edge region $(\mathbf{a}-\mathbf{c})$ and height profiles of the indicated lines $\left(\mathbf{a}^{\prime}-\mathbf{c}^{\prime}\right)$ : before telmisartan $\left(\mathbf{a}, \mathbf{a}^{\prime}\right), 10 \mathrm{~min}\left(\mathbf{b}, \mathbf{b}^{\prime}\right)$, and 20 $\min \left(\mathbf{c}, \mathbf{c}^{\prime}\right)$ after telmisartan treatment.

(table 1). Stimulation with Ang II for 20 min significantly increased the cellular spring constant in MCs from $0.039 \pm 0.011$ to $0.109 \pm 0.019 \mathrm{~N} / \mathrm{m}$, while pretreatment with telmisartan abolished the effects of Ang II (cellular spring constant $0.051 \pm 0.016 \mathrm{~N} / \mathrm{m}$, after incubation with Ang II with telmisartan). These results indicate that MC stiffening increased with Ang II treatment, and that telmisartan treatment prevents this effect. Figure 6 shows a representative retraction half curve of the forcedistance curve in MCs after treatment with Ang II or the combination of Ang II with telmisartan. With Ang II treatment, a slight pull-off event was observed (fig. 1a). With telmisartan pretreatment, no clear pull-off event was observed (fig. 1b). Table 1 shows the adhesion force results measured between the tip and cell surface. After Ang II stimulation, the adhesive force changed slightly, although the difference between this force and that in the no-treatment group was not statistically significant. However, telmisartan-pretreated cells showed smaller pull-off forces than the MCs before treatment ( $\mathrm{p}<$ $0.005)$. 
Fig. 5. Histogram showing spring constant distributions of MCs after Ang II stimulation with or without telmisartan pretreatment. Measurements were calculated from the slope of the approach curve.

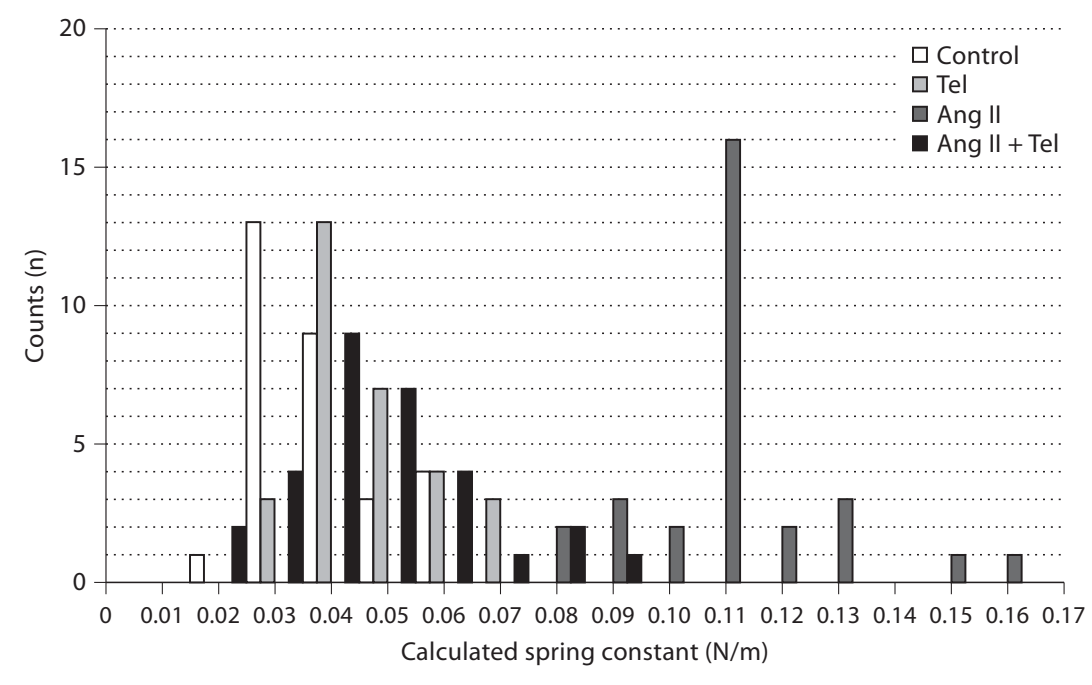

Table 1. Calculated spring constant and adhesion forces of live MCs ( $=30$ ) before and 20 min after Ang II stimulation with or without telmisartan

\begin{tabular}{lll}
\hline & $\begin{array}{l}\text { Calculated spring } \\
\text { constant, N/m }\end{array}$ & $\begin{array}{l}\text { Adhesive force } \\
\mathrm{nN}\end{array}$ \\
\hline Control & $0.039 \pm 0.011$ & $0.49 \pm 0.22$ \\
Telmisartan & $0.047 \pm 0.012$ & $0.22 \pm 0.06^{\mathrm{b}}$ \\
Ang II & $0.109 \pm 0.019^{*}$ & $0.40 \pm 0.25$ \\
Ang II+telmisartan & $0.051 \pm 0.016^{* *, a}$ & $0.27 \pm 0.14^{\mathrm{b}}$ \\
\hline
\end{tabular}

${ }^{*} \mathrm{p}<0.0001$ vs. control; ${ }^{* *} \mathrm{p}<0.05$ vs. control; ${ }^{\mathrm{a}} \mathrm{p}<0.005$ vs. Ang II; ${ }^{\mathrm{b}} \mathrm{p}<0.005$ vs. control.

MC contraction and to obtain the stiffness same time in a live cell surface. Using AFM, Hillebrand et al. [15] reported that aldosterone causes endothelial cell stiffness and that eplerenone effectively prevents endothelial growth and stiffening. Our work also implicates telmisartan in the mechanical modulation of MCs. We focused our experiments on the alteration of two major mechanical properties implicated in the contractile response of MCs: stiffness and adhesion force. As shown in table 1, Ang II-influenced stiffening of MCs was ameliorated by telmisartan. The mechanical stiffness of a cell might be important for proper functioning and is altered in pathologic states; for instance, the stiffness of endothelial cells is increased by aldosterone stimulation and is influenced 
Fig. 6. Representative retraction half of the force-distance curve in MCs after Ang II stimulation (a) and combination of Ang II with telmisartan (b).

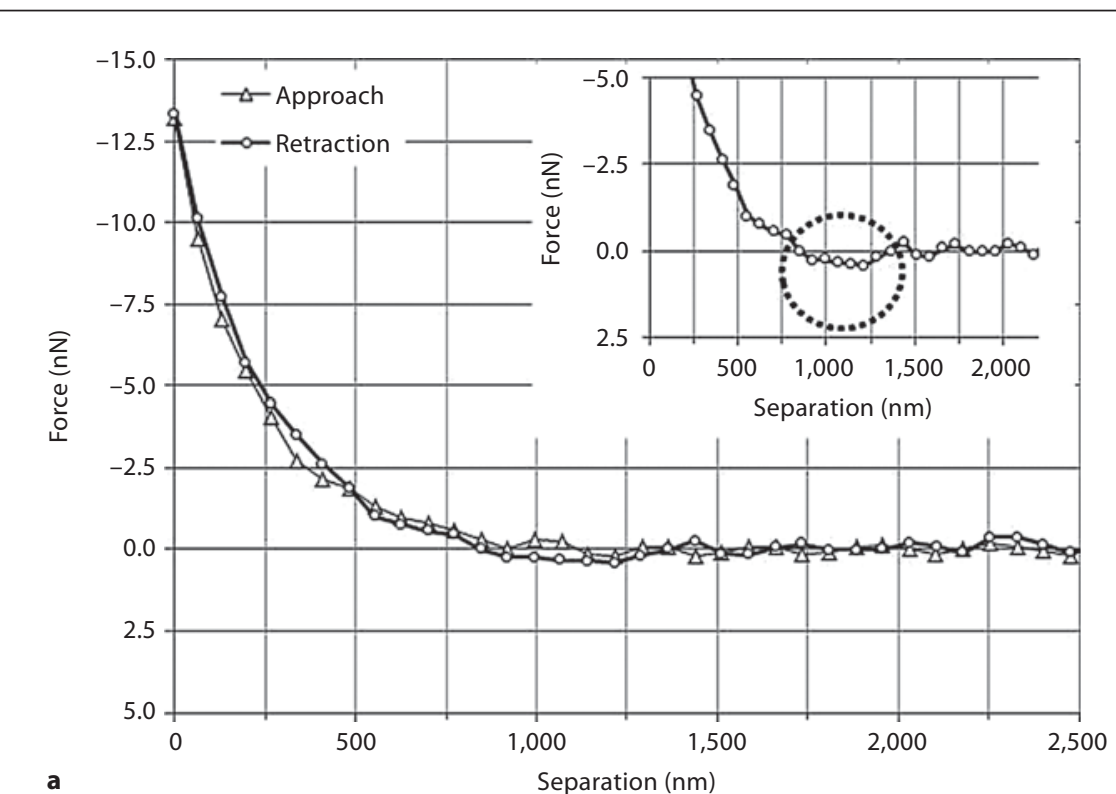

Separation $(\mathrm{nm})$

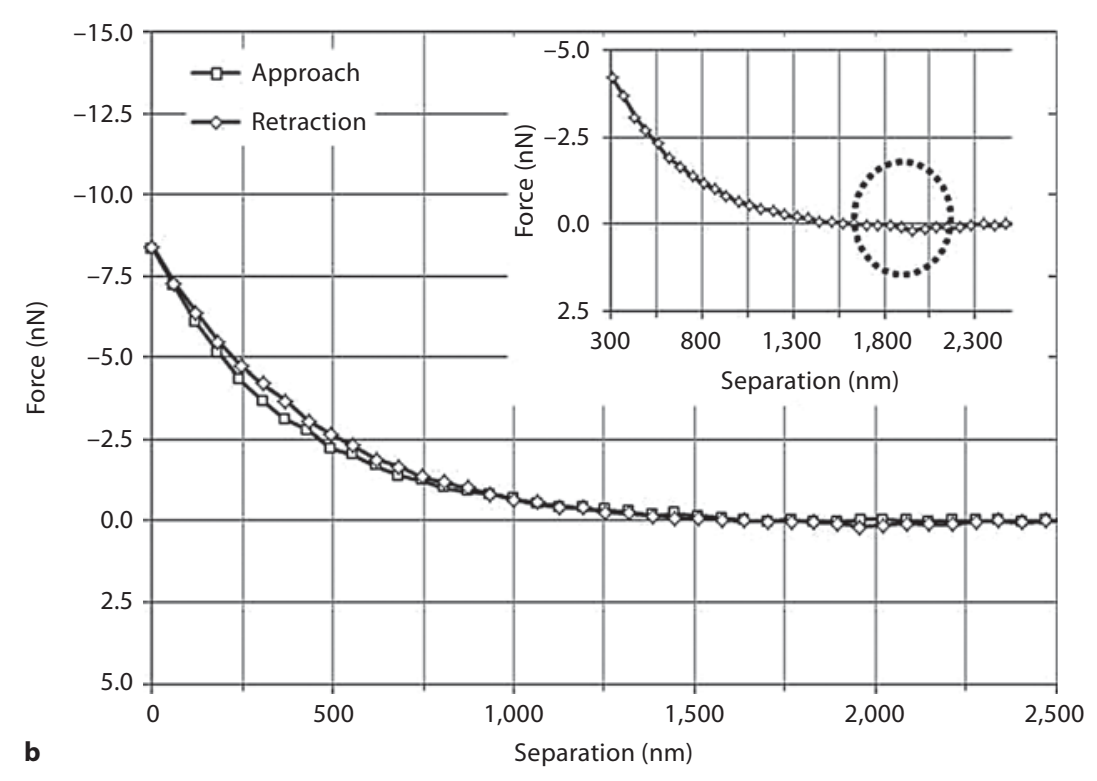

by extracellular sodium concentration [16, 17]. Increased vulnerability to mechanical stress is also likely in a stiffened cell state [18]. Ang II increases MC stiffness, thereby altering $\mathrm{MC}$ vulnerability and cell-cell interactions and remodeling the mesangium. Telmisartan on MCs could prevent these deleterious effects. Several potential explanations may be offered for the mechanical change of MCs on Ang II and/or telmisartan in this study. Changes in cell morphology and mechanics have been demonstrated to be associated with dynamic alteration of the cytoskel- eton, such as the actin-myosin system [12]. Ang II stimulation could be involved in the increase of actin cytoskeleton activity and reorganization which resulted in a significant change of the elastic modulus of the cell [12]. Cytoskeleton elements, including the actin-myosin system, should be taken into consideration in future research to determine their possible contribution to the mechanical response.

MCs express a variety of adhesion molecules responsible for generating adhesion forces in cell-cell and cell- 
extracellular matrix interactions. In this study, changes in the adhesive force of cell surfaces were measured based on cell-tip interactions in AFM. We did not observe a significant change in adhesive force after Ang II stimulation, however we did find that the adhesive force was significantly reduced in the telmisartan-treated group. Several factors could have contributed to the reduction in adhesive force in the telmisartan-treated group. Previous studies demonstrated that decreased cellular adhesive force corresponds to decreased expression of chondrocyte membrane proteins such as integrin and collagen [14]. Link et al. [19] reported that telmisartan inhibited the expression of integrin independent of Ang II. Thus, the reduction in force between MCs and the tip may be due to telmisartan-induced biochemical modifications of the MCs. However, it was beyond the scope of this study to investigate the mechanisms underlying the observed changes in MC adhesive force.

AFM imaging of live cells is complicated and requires the maintenance of physiologic conditions [20]. AFM cell imaging in air conditions is attributed to the increasing hardness of the cell by dehydration [21]. Thus, all experiments were performed in liquid condition. This is the first study to focus on real-time AFM imaging of single live cell dynamics and mechanical changes in live cells to examine the telmisartan effect on Ang II in MCs. It was better to use fixed cells for the quantitative analysis of visual changes such as cell height and volume in cells. However, cell fixation might preclude measurement of the direct and minute mechanical changes of cells because of the increased rigidity with fixation.

Our results revealed several advantages. The ability to image and study the surface of living cells is one of the important aspects of AFM in our investigation. Moreover, mechanical properties, stiffness, and adhesive force were all directly measured simultaneously using AFM. This study should serve as a fundamental guide for general users, for the successful imaging and measuring mechanical force of live cells by AFM. Using specific ARB, we demonstrated that a mechanical response recorded on a single $\mathrm{MC}$ can be used to investigate the contribution of specific mechanism of renoprotection. Moreover, AFM can provide important information for elucidating the biological and physical mechanism of renal injury.

\section{Conclusion}

Using AFM, we demonstrated that morphological and mechanical changes in Ang II-stimulated MCs were effectively prevented by telmisartan treatment. Measuring the stiffness and adhesive properties of MCs after telmisartan treatment allowed us to explore the roles of ARBs in MC structure and renal protection. Although the mechanisms underlying physical changes in MCs have not been fully elucidated, real-time AFM imaging can provide non-invasive measurements of cellular processes in living cells to aid in the determination of these mechanisms.

\section{Acknowledgment}

This study was supported by a grant from the Kyung Hee University Program for Young Researchers in Medical Science (KHU2007-1503).

\section{Disclosure Statement}

The authors have no conflicts of interest to disclose.

\section{References}

1 Mene P, Simonson MS, Dunn MJ: Physiology of the mesangial cell. Physiol Rev 1989;69: 1347-1424.

-2 Burridge K, Chrzanowska-Wodnicka M: Focal adhesions, contractility, and signaling. Annu Rev Cell Dev Biol 1996;12:463518.

-3 Parving HH, Lehnert H, Brochner-Mortensen J, Gomis R, Andersen S, Arner P: The effect of irbesartan on the development of diabetic nephropathy in patients with type 2 diabetes. N Engl J Med 2001;345:870-878.
-4 Ogawa S, Mori T, Nako K, Kato T, Takeuchi $\mathrm{K}$, Ito S: Angiotensin II type 1 receptor blockers reduce urinary oxidative stress markers in hypertensive diabetic nephropathy. Hypertension 2006;47:699-705.

-5 Villa L, Boor P, Konieczny A, Kunter U, van Roeyen CR, Denecke B, Gan L, Kupper MB, Hoffmann K, Eitner F, Ostendorf T, Floege J: Effects and mechanisms of angiotensin II receptor blockade with telmisartan in a normotensive model of mesangioproliferative nephritis. Nephrol Dial Transplant 2011;26: 3131-3143.
-6 Tsunenari I, Ohmura T, Seidler R, Chachin M, Hayashi T, Konomi A, Matsumaru T, Sumida T, Hayashi N, Horie Y: Renoprotective effects of telmisartan in the 5/6 nephrectomised rats. J Renin Angiotensin Aldosterone Syst 2007;8:93-100.

7 Binnig G, Quate CF, Gerber C: Atomic force microscope. Phys Rev Lett 1986;56:930-933.

8 Volle CB, Ferguson MA, Aidala KE, Spain EM, Nunez ME: Quantitative changes in the elasticity and adhesive properties of Escherichia coli ZK1056 prey cells during predation by Bdellovibrio bacteriovorus 109J. Langmuir 2008;24:8102-8110. 
9 Radmacher M, Fritz M, Kacher CM, Cleveland JP, Hansma PK: Measuring the viscoelastic properties of human platelets with the atomic force microscope. Biophys J 1996;70: 556-567.

- 10 Schneider SW, Yano Y, Sumpio BE, Jena BP, Geibel JP, Gekle M, Oberleithner H: Rapid aldosterone-induced cell volume increase of endothelial cells measured by the atomic force microscope. Cell Biol Int 1997;21:759-768.

-11 Lee GJ, Park EJ, Choi S, Park JH, Jeong KH, Kim KS, Lee SH, Park HK: Observation of angiotensin II-induced changes in fixed and live mesangial cells by atomic force microscopy. Micron 2010;41:220-226.

-12 Cuerrier CM, Benoit M, Guillemette G, Gobeil F Jr, Grandbois M: Real-time monitoring of angiotensin II-induced contractile response and cytoskeleton remodeling in individual cells by atomic force microscopy. Pflugers Arch 2009;457:1361-1372.
13 Elger M, Drenckhahn D, Nobiling R, Mundel P, Kriz W: Cultured rat mesangial cells contain smooth muscle $\alpha$-actin not found in vivo. Am J Pathol 1993;142:497-509.

14 Hsieh CH, Lin YH, Lin S, Tsai-Wu JJ, Herbert $\mathrm{Wu} \mathrm{CH}$, Jiang CC: Surface ultrastructure and mechanical property of human chondrocyte revealed by atomic force microscopy. Osteoarthritis Cartilage 2008; 16: 480-488.

15 Hillebrand U, Schillers H, Riethmuller C, Stock C, Wilhelmi M, Oberleithner H, Hausberg M: Dose-dependent endothelial cell growth and stiffening by aldosterone: endothelial protection by eplerenone. J Hypertens 2007;25:639-647.

16 Oberleithner H: Aldosterone makes human endothelium stiff and vulnerable. Kidney Int 2005;67:1680-1682.

17 Oberleithner H, Riethmuller C, Schillers H, MacGregor GA, de Wardener HE, Hausberg M: Plasma sodium stiffens vascular endothelium and reduces nitric oxide release. Proc Natl Acad Sci USA 2007;104:16281-16286.
18 Oberleithner H, Riethmuller C, Ludwig T, Hausberg M, Schillers H: Aldosterone remodels human endothelium. Acta Physiol (Oxf) 2006;187:305-312.

19 Link A, Lenz M, Legner D, Bohm M, Nickenig G: Telmisartan inhibits $\beta_{2}$-integrin MAC-1 expression in human T-lymphocytes. J Hypertens 2006;24:1891-1898.

20 Murphy MF, Lalor MJ, Manning FC, Lilley F, Crosby SR, Randall C, Burton DR: Comparative study of the conditions required to image live human epithelial and fibroblast cells using atomic force microscopy. Microsc Res Tech 2006;69:757-765.

21 Weyn B, Kalle W, Kumar-Singh S, Van Marck E, Tanke H, Jacob W: Atomic force microscopy: Influence of air drying and fixation on the morphology and viscoelasticity of cultured cells. J Microsc 1998;189:172180. 